\title{
Paying Attention to the Pandemic: \\ Knowledge of COVID-19 Facts by News Source and Demographics
}

\author{
Molly M. King
}

The structured inequalities built into our sociotechnical institutions shape access to knowledge. During the COVID-19 pandemic, knowledge acquisition was shaped by news sources, class, and race. Through analysis of nationally representative data using logistic models, this study reveals how the use of different news sources differentially shapes access to accurate knowledge about COVID-19 topics for different demographics. Those who rely on informal and local news sources have the largest knowledge gaps about these topics, while those who seek information from national or international news outlets and politicians have the most accurate knowledge. Race and class influence knowledge of government operations, public health, and science of COVID-19. In particular, Black people, people with less education, and those with lower incomes are significantly less likely to have accurate knowledge about COVID-19, all else equal. These findings have implications for knowledge dissemination that impacts public health, as well as for how news media target different audiences in an increasingly fractured landscape.

INTRODUCTION

The abrupt arrival of COVID-19 in global awareness in early spring 2020 compelled a media blitz to inform the public about the new pandemic. Given the rapidly developing landscape of knowledge about COVID-19, as well as the importance of the disease in people's lives, more than eight in ten Americans reported following news about the outbreak very or fairly closely in June, 2020 (see Table 2). Having up-to-date, accurate knowledge of science and public health policy had consequences not only for one's own health, but also for the well-being of one's family and community. Yet the challenges in sorting through this information are substantial (Metaxa-Kakavouli \& Torres-Echeverry, 2017).

Understanding these challenges in garnering accurate knowledge about an entirely new topic provides an unusual opportunity to study the social dynamics of knowledge inequalities in real time. To do this, this study investigates how news source, class, and race and ethnicity influence accurate knowledge about COVID-19.

I begin by defining knowledge as true belief. Next, I review what we know about Americans' knowledge of COVID-19-related facts. Then, I briefly review relevant research on knowledge acquisition through internet media -- including news aggregators and search engines, social networks and social media -- as well as more traditional TV, print, and radio news. I also briefly discuss what we know about different identity groups' information seeking patterns during the pandemic. Following this review, I empirically investigate the joint relationship between news source and knowledge of the COVID-19 pandemic. The study illuminates how knowledge of the COVID-19 pandemic is structured by race and ethnicity, family income, and education.

Preprint v2 | September 22, 2021 


\section{Knowledge Inequalities}

Sociology of knowledge aims to understand the existential foundations of forms of thought, including facts (Camic \& Gross, 2001). For the purpose of this research, I follow philosophy in defining knowledge, in the 'lightweight' or 'weak' sense, as true belief (Ichikawa \& Steup, 2012). We can determine whether a belief is justified depending on whether the process through which it was formed is a "reliable source of true beliefs" (Truncellito, 2021, p. 9).

Where might systematic variations in the distribution of knowledge come from? Understanding the causes at the root of knowledge differences can point to systemic inequities in information consumption, such as those that result from the media. Gaps in knowledge come from inequalities in "the possession and usage of information and communication sources in a particular society" (Yu, 2006, p. 231). Knowledge inequalities are the product of the unequal distributions of information resources (Britz, 2004).

Knowledge gaps may be particularly relevant in sorting through misinformation in rapidly developing news environments, such as that with the current coronavirus pandemic. Rather than more information being the solution, it is rather the torrent of new research and media that makes it so difficult to adjudicate what is factual (O'Connor \& Weatherall, 2019, 2020). Baum et al. (2020) surveyed over 21,000 respondents, asking them questions about 11 factual knowledge questions related to COVID-19. At least one in ten Americans held misperceptions about COVID-19 in all but three of the questions during all six waves.

\section{$\underline{\text { News Source }}$}

Demographic preferences for news consumption can vary dramatically among different news media. Many prior studies have evaluated information seeking behaviors and needs (Case \& Given, 2016). However, the study of new media on formal knowledge is relatively new (Swidler \& Arditi, 1994).

Online news is a key source of knowledge for many Americans. Seventy-two percent of people in the U.S. report getting news online, including on social media (Newman, Richard Fletcher, Schulz, And1, \& Kleis Nielsen, 2020). Mobile news aggregators are increasingly important forces in the media landscape, with 35\% of people in the U.S. reporting using an aggregator each week and 7\% using one as their main gateway to news (Newman et al., 2020). Research reveals widespread algorithmic bias online, shaping the news people receive (Eubanks, 2018; Noble, 2018; O'Neil, 2016). Email is also an increasingly important format, with one in five Americans receiving a newsletter update direct from a news publisher each week, and half of these reporting it was their primary way of accessing news (Newman et al., 2020).

Information also spreads through informal social networks online. In 2020,48\% of people in the U.S. considered social media a source of news, a figure which has almost doubled since 2013 (Newman et al., 2020). Both online and off, "many of our beliefs - perhaps most of them..." are formed "on the basis of what other people tell us. We trust and learn from one another" (O'Connor \& Weatherall, 2019, p. 8). Individuals shape their social media feeds to create social environments 
that agree with their outlooks and limit the opposing facts to which they are exposed (O'Connor \& Weatherall, 2019; Pariser, 2011).

Among TV, radio and print consumers, 28\% of Americans reported getting their news from local TV news, and only 18\% from a local or regional newspaper, on a weekly basis (Newman et al., 2020). Only 14\% reported weekly use of a local television news website and $9 \%$ of a regional or local newspaper website (Newman et al., 2020). This may be partly due to difficulties discovering local news online because Google's search returns favor a small number of large news outlets over local news (Diakopoulos, 2019; Fischer, Jaidka, \& Lelkes, 2020).

In short, psychological and cognitive biases (DiMaggio, 1997) are colliding with the technological realities of our time to create novel knowledge inequities (Mohammed, 2012). These inequalities and biases are critical because nearly one in two Americans seeks out news on social media websites (Newman et al., 2020). Many people consume news from Facebook-affiliated social companies, including 35\% from Facebook, 9\% from Facebook Messenger, and 4\% from WhatsApp (Newman et al., 2020, p. 87). An increasing proportion of Americans (24\%) also get their news from YouTube (Newman et al., 2020; Pew Research Center, 2017). About one in five people in the U.S. turn primarily to social media for their political news, and these tend to be the least engaged and knowledgeable about coronavirus news (Mitchell, Jurkowitz, Oliphant, \& Shearer, 2020).

\section{News Source \& Knowledge}

One factor that has a substantial influence on our knowledge is the source of our news. This study is primarily concerned with this relationship: Consumption of which news source is most likely to predict accurate knowledge of COVID-19 topics? Does this vary by topic? Existing work says that media consumption matters, but not how. The variety of media through which people seek news reflects the variety of reasons people use news media -- not just a desire to be informed. These myriad motivations also influence the quality of knowledge we come away with after consuming news (Fisher, 2016).

Type of news source also has implications for who consumes the most misinformation. For example, people who use social media as their most common method of consuming political and election news were the most likely to have heard 'a lot' (26\%) about the (false) conspiracy theory that the pandemic was intentionally planned, followed by those who got their news through local TV (20\%) (Mitchell et al., 2020). Prior to the presidential election, 67\% of U.S. adults reported concern "about what is real and what is fake on the internet" related to news (Newman et al., 2020, p. 18). The largest proportion (35\%) reported that they were most concerned about distinguishing misinformation on the Facebook platform (Newman et al., 2020, p. 19). These concerns are well-founded; among social media users, the average percent of actually false claims about COVID-19 identified as accurate ranged from 20\% (Twitter, TikTok, and Youtube users) to 31\% (WhatsApp users) (Baum, Ognyanova, et al., 2020). Many forms of modern news media, focused on ephemera, provide the consumer with little detailed knowledge about the causality or meaning of events (Nielsen, 2017), making it even more challenging for the public to filter accurate information. 
The literature has largely measured feelings about news sources using metrics of trust. Trust in media has been measured in a variety of ways, focusing on medium (press, television, etc.), source (provider), and message credibility (see Fisher, 2016 for a review). Only 29\% of people in the U.S. report trusting most news most of the time. However, $45 \%$ of people reported trusting the news that they themselves used (Newman et al., 2020). Local news is viewed as more trustworthy than national news, particularly among Democrats (Knight Foundation \& Gallup, 2019; Newman et al., 2020). ${ }^{1}$ Though generally, the lay public's trust in or assessment of quality of a news source is predictive of the factual quality of the source (Bachmann, Eisenegger, \& Ingenhoff, 2021), people often consume news they do not trust, depending on their motivations (Fisher, 2016). As a result, measures of trust have important limitations when it comes to understanding the public's knowledge. For example, some of the most-viewed news brands on television and online (Fox and CNN) are also the most strongly distrusted (Newman et al., 2020). Fisher (2016) warns that we cannot assume "that media users will be motivated by the normative ideal of being a well-informed citizen in their consumption of news" (p. 10).

Although trust is thus related to knowledge, the two are distinct concepts. We are more likely to trust those who espouse our current worldview (O'Connor \& Weatherall, 2019). Trust in social media and private news sources is negatively associated with both knowledge about COVID-19 and the practice of social distancing behavior, compared to trust in government information sources (Fridman, Lucas, Henke, \& Zigler, 2020). Furthermore, knowledge mediates the relationship between trust in government sources and social distancing behavior (Fridman et al., 2020). With the focus of their study on trust and behavior, Fridman et al. (2020) did not report any analysis on the relationship between information source and accuracy of knowledge.

On average, U.S. adults indicated they prefer that scientists and government public health leadership manage the response to the COVID-19 pandemic (McFadden, Malik, Aguolu, Willebrand, \& Omer, 2020). Generally, U.S. adults trust scientists' knowledge about COVID-19; however, this trust varies widely based on demographic characteristics (Evans \& Hargittai, 2020). It follows that different demographic groups would follow different news sources for emerging information about COVID-19 and the pandemic response.

This suggests news source is likely an important factor in predicting knowledge about COVID-19; my analyses test whether news source has a significant relationship net of other factors. I derive several hypotheses:

- Hypothesis 1. Those who consume the most news from national or international sources will have more knowledge about COVID-19 topics than those acquiring news from local sources.

\footnotetext{
${ }^{1}$ In the analyses I report below, adding indicator variables for party affiliation (Democrat, Republican, or Independent) had no significant influence except for one significant effect of being Independent on knowledge of the state lockdown response to COVID-19. However, excluding respondents without a party affiliation from the analysis removed 947 respondents from the analytical dataset ( $\sim 10 \%$ of total respondents). Therefore, I did not include party affiliation in this analysis.
} 
- Hypothesis 2. Those who consume the most news from public health sources will have more accurate knowledge about COVID-19 topics than those acquiring news from political sources.

- Hypothesis 3. Those who consume the most news from formal sources will have more knowledge about COVID-19 topics than those acquiring news from informal sources.

\section{$\underline{\text { Knowledge Inequalities by Class and Race }}$}

We do know that different groups consume different types of news. As a result, we expect people to have different levels of knowledge about the COVID-19 pandemic based on their class and race and ethnicity. Each of these serves as a moderating variable later in the analysis.

Because of a history of medical racism and research malpractice, Black Americans are generally slightly less trusting of researchers and scientists than whites (Gamble, 1997; Sullivan, 2020). As a result, non-white populations express greater trust in non-government information sources (Fridman et al., 2020). ${ }^{2}$ During spring 2020, Black Americans were more likely than white and Hispanic adults to closely follow news about the outbreak and more likely to discuss it with others (Mitchell \& Jurkowitz, 2020). Black adults were significantly more likely than whites to be closely following the health impact on people like them, the ability of U.S. hospitals to treat patients, and the number of cases and deaths (Mitchell \& Jurkowitz, 2020). Despite this attentiveness, non-whites had lower levels of knowledge about the pandemic. In fall of 2020, Black Americans had the highest average level of belief in 11 false claims about COVID-19, followed by Hispanic Americans. Both groups were also more likely than whites to respond that they are 'not sure' whether the false claims are true (Baum, Ognyanova, et al., 2020).

Thoroughly documented digital inequalities (e.g., Robinson et al., 2020) influence what type of news people consume. Those who get their news primarily through local TV and social media are more likely to have lower incomes and less education than those who turn primarily to news websites or apps, cable or network TV, or radio or print news (Mitchell et al., 2020). More highly educated adults are more likely to follow international news (Pew Research Center, 2018). Differences in reporting on these different mediums is further complicated by their different audiences' trust of science. Education and family income are not always significant predictors of trust in science, although people with more education generally support science more (reviewed in Evans \& Hargittai, 2020).

These moderating variables -- race and ethnicity, family income, and education -- and several controls join with the news sources that respondents use most to form the basis for the analysis of knowledge that follows. Based on the above review of the literature, I have several hypotheses about these moderating variables:

\footnotetext{
${ }^{2}$ However, when asked how much they trusted each person or organization "to do the right thing to best handle the current coronavirus outbreak," there are negligible differences among racial groups in very high levels of trust of the CDC, hospitals and doctors, and scientists and researchers. There were stark Black-white racial divides in trust, however, for this question for Donald Trump and the White House and for Joe Biden (Baum, Lin, et al., 2020).
} 
- Hypothesis 4. Race and ethnicity, family income, and educational attainment jointly moderate the relationship between news source and knowledge.

- Hypothesis 5. Whites will have more knowledge about COVID-19 topics than non-whites.

- Hypothesis 6. Those with higher family incomes will have more knowledge about COVID-19 topics.

- Hypothesis 7. Those with more education will have more knowledge about COVID-19 topics.

The literature suggests news source might be an important factor in explaining knowledge of COVID-19 topics; this analysis will test whether it is, net of other factors, as well as assessing the relative importance of these sociodemographic contextual variables.

\section{Methods}

\section{$\underline{\text { Data }}$}

In this analysis, I investigate factual knowledge of the pandemic using the Pew Pathways June 2020 American Trends Panel Wave 68 Survey (Pew Research Center, 2020). This nationally representative survey of adults in the United States includes questions about knowledge of and news consumption related to the COVID-19 pandemic. The Wave 68 survey used address-based sampling with a response rate of 88\% (Pew Research Center, 2020). As discussed in more detail below, I used wave-specific probability sampling weights provided by Pew Research Center to account for the multistep survey sampling design to yield statistical estimates representative of the U.S. adult population. All analyses were performed using Stata/MP v16.1. In keeping with recommendations on transparent and open social science (Freese \& King, 2018), so that readers can see all analysis decisions for themselves, annotated code and additional methodological comments are available at the Open Science Framework project page (osf.io/qf624/).

The analytic dataset was generated using listwise deletion of observations with any missing data on any variables of interest. Our sample started with 9,654 respondents from the original Wave 68 survey of the Pew American trends Panel. I excluded 383 respondents (3.97\% of all cases) for

missing data on the measure of news source. I excluded an additional 603 observations $(6.25 \%$ of all cases) for missing data on one or more moderator or control variables, resulting in a final analytic sample of 8,668 observations.

\section{Outcome Variable: Knowledge}

The Pew June 2020 American Trends Panel Wave 68 Survey (Pew Research Center, 2020) includes several questions about knowledge of the COVID-19 pandemic:

1. Fauci: "Do you happen to know who Anthony Fauci is?" (Correct answer is "An infectious disease expert and government health adviser.") 
2. State Response: "As far as you know, how did states in the U.S. respond during the coronavirus outbreak?" (Correct answer is "Some states in the U.S. have not had a statewide stay-at-home order.")

3. Antibody: "As far as you know, are antibody tests for the coronavirus (also known as serology tests) intended to detect..." (Correct answer is "A previous infection")

These questions correspond to three very different realms of factual understanding of the COVID-19 pandemic: government operations (Fauci), public health (state response), and scientific understanding (antibody). These different areas of knowledge provide a broad overview of the public's understanding of COVID-19 topics during the early months of the pandemic.

In its raw form, each question is coded based on the respondent's answer to the multiple-choice question. I recoded each variable to a binary form: correct answers are coded 1 and respondents who chose any of the incorrect options are coded 0 . Those who respond 'don't know' or 'refused' for each knowledge question are included among those who are 'incorrect.'

\section{Explanatory Variable: News Source}

The survey asked respondents "which of these sources do you rely on most for news about the coronavirus outbreak?” (Pew Research Center, 2020; Shearer, 2020). There were ten mutually exclusive choices available to respondents (Table 1). I initially analyzed the full models with all news source categories separate (see osf.io/qf624/). To facilitate interpretation of results and consolidate categories respondents with small sample sizes, I grouped news sources together based on their structurally similar roles (see Table 1).

Table 1. News source relied on most for news about the coronavirus outbreak: Original options available to respondents and analytical groupings used for regression analysis. Data: Pew June 2020 American Trends Panel Wave 68 survey.

\begin{tabular}{|l|l|}
\hline $\begin{array}{l}\text { News Source Raw: } \\
\text { Choices available to respondents }\end{array}$ & $\begin{array}{l}\text { News Source Recoded: } \\
\text { Grouping used for analysis }\end{array}$ \\
\hline $\begin{array}{l}\text { International news outlets } \\
\text { National news outlets }\end{array}$ & $\begin{array}{l}\text { International and national news } \\
\text { (baseline) }\end{array}$ \\
\hline Local news outlets & Local news \\
\hline $\begin{array}{l}\text { Trump and his coronavirus task force } \\
\text { Joe Biden and his campaign } \\
\text { State and local elected officials and their offices }\end{array}$ & Political sources \\
\hline Public health organizations and officials & Public health organizations and officials \\
\hline $\begin{array}{l}\text { Friends, family and neighbors } \\
\text { Community or neighborhood newsletters or listservs } \\
\text { Online forums or discussion groups }\end{array}$ & Informal networks \\
\hline
\end{tabular}


The news source variable does introduce several limitations to this study. The variable available from the Pew ATP dataset allows respondents to choose only one source that they rely on primarily for news about the coronavirus outbreak. This prevents distinguishing respondents who may be more informed because they triangulate their information or because they are more avid news consumers. Second, more granularity in this news source variable would enable a better understanding of the routes respondents are taking to consume their news (e.g., Newman et al. 2020). Finally, oversampling respondents consuming news from underrepresented sources would help better understand the use of those sources.

\section{Moderating Variables: The Race and Class of Knowledge Acquisition}

Several variables are introduced as moderating variables: race and ethnicity; family income; and educational attainment. More details on each of these can be found in the Methodological Appendix (osf.io/qf624/).

The Pew data include a five-category, mutually exclusive race variable for each respondent and a separate ethnicity question. Respondents who answered "don't know" or refused to answer were excluded from the analysis. I combined these two race and ethnicity questions into a race 'pentagon' classification (Howell \& Emerson, 2017).

Social class both creates and is produced by differences in knowledge. I use family income and education as measures of social class. Respondents were initially offered nine family income categories, and I collapsed these categories such that the resulting six groupings would each have at least 1,000 respondents (see Table MA.1 in Methodological Appendix).

I employ the original five categories from the Pew dataset: less than high school (reference category); completed high school; some college; bachelor's degree; and graduate or professional degree. Though education and family income are collinear, education would be expected to have an independent effect on the ability to consume and interpret the news, so both are included in all models with controls.

\section{Controls: Potential Confounder Variables}

The analyses also introduce several variables which serve both as contextual and sociodemographic controls for the other characteristics of respondents which may have influenced their knowledge of the COVID-19 topics. Controls for how closely respondents follow the news, age, gender, and religion are all included because of their correlation with both news source and knowledge on at least one question.

Regardless of which media source respondents follow, the degree to which they closely follow the news will also influence their knowledge of the pandemic, so I controlled for self-reports of how closely respondents follow "news about the outbreak of the coronavirus strain known as COVID-19." 
Older adults are more likely to follow local news (Pew Research Center, 2018) and express trust in government sources (Fridman et al., 2020). Younger groups trust private sources and social networks (Fridman et al., 2020) and have greater beliefs in misinformation about COVID-19 (Baum, Ognyanova, et al., 2020). I use the categorical age groups provided by Pew: 18-29; 30-49; 50-64; and 65 and over.

Previous literature is mixed on gender and support for science (reviewed in Evans \& Hargittai, 2020) and knowledge amount COVID-19 (Baum, Ognyanova, et al., 2020). I am limited by available data to coding gender as a binary variable.

Conservative Protestant affiliation is associated with reduced likelihood of knowledge of science (Roos, 2016). However, this association seems to be largely the result of a disagreement over values or morals, rather than a disagreement about facts (Evans, 2018; Evans \& Evans, 2008). The "most salient factor" that explains disputes over scientific findings is the ideology of Christian nationalism: debates over facts "reflect politically motivated denials of scientific facts that threaten Christian nationalism's claims to epistemic and cultural authority” (Perry, Baker, \& Grubbs, 2021, p. 1). In a study of trust in the expertise and shared values of scientists during COVID-19, conservative Protestants and Catholics were skeptical of scientists' knowledge (Evans \& Hargittai, 2020). Political conservatives were also skeptical of the science, but this effect was largely mediated through beliefs in Christian nationalism (Baker, Perry, \& Whitehead, 2020). ${ }^{3}$ To control for religion, I follow Evans and Hargittai (2020) in transforming the Pew survey questions for present religion and evangelical Christian into a single religion variable (see Table MA.2 in Methodological Appendix).

\section{$\underline{\text { Descriptive Statistics }}$}

First, I provide a set of descriptive statistics for each question. To evaluate the proportion answering correctly, I estimate the population mean (and standard error) for the binary variable indicating correct answer, within a given demographic group:

$$
\text { mean }_{C}=\frac{P(y=1)}{N} \text {. }
$$

In this model, $N$ is the size of the sample responding to that question, and $y=1$ is the outcome variable (correct answer). The probability of answering correctly for the population $(P(y=1))$ is calculated out of all individuals who provided a correct or incorrect answer (including those who respond 'don't know'). Hence, the mean proportion correct for the population for a single knowledge question ( mean $_{C}$ ) is equal to the survey-weighted probability of getting the knowledge question correct divided by the total number of survey respondents within the group.

Summary statistics for all variables are presented in Table 2. This table presents descriptive statistics of the proportion of each group who answered each of the three knowledge questions correctly,

\footnotetext{
${ }^{3}$ I repeated my analysis including political party affiliation as a control, and the results were largely
} the same (see Table A2 at osf.io/gf624/). 
Table 2. Descriptive statistics presenting overall population distributions and the proportion responding correctly to each knowledge question and standard deviation within each variable group. Proportions and standard deviations are weighted for the survey sampling design. Data: Pew June 2020 American Trends Panel Wave 68 survey.

\begin{tabular}{|c|c|c|c|c|c|c|c|c|}
\hline & \multicolumn{2}{|c|}{ Overall } & \multicolumn{2}{|c|}{ Correct: Fauci } & \multicolumn{2}{|c|}{$\begin{array}{c}\text { Correct: State } \\
\text { Response }\end{array}$} & \multicolumn{2}{|c|}{ Correct: Antibody } \\
\hline & Proportion & SD & Proportion & SD & Proportion & SD & Proportion & SD \\
\hline \multicolumn{9}{|c|}{ News Source relies most on for news about coronavirus outbreak } \\
\hline Int'l / Nat'l & 0.311 & 0.008 & 0.804 & 0.397 & 0.599 & 0.490 & 0.675 & 0.469 \\
\hline Local & 0.173 & 0.007 & 0.572 & 0.495 & 0.433 & 0.496 & 0.451 & 0.498 \\
\hline Politicians & 0.250 & 0.007 & 0.769 & 0.421 & 0.574 & 0.495 & 0.644 & 0.479 \\
\hline Pub. Health & 0.181 & 0.006 & 0.715 & 0.452 & 0.570 & 0.495 & 0.671 & 0.470 \\
\hline Informal & 0.085 & 0.006 & 0.431 & 0.496 & 0.429 & 0.495 & 0.423 & 0.495 \\
\hline \multicolumn{9}{|l|}{ Racel Ethnicity } \\
\hline White & 0.661 & 0.009 & 0.779 & 0.415 & 0.589 & 0.492 & 0.698 & 0.459 \\
\hline Black & 0.106 & 0.006 & 0.524 & 0.500 & 0.378 & 0.485 & 0.347 & 0.476 \\
\hline Asian & 0.053 & 0.004 & 0.735 & 0.442 & 0.572 & 0.496 & 0.560 & 0.497 \\
\hline Hispanic & 0.153 & 0.007 & 0.526 & 0.499 & 0.461 & 0.499 & 0.422 & 0.494 \\
\hline Other/mixed & 0.027 & 0.003 & 0.654 & 0.477 & 0.515 & 0.501 & 0.521 & 0.501 \\
\hline \multicolumn{9}{|l|}{ Family Income } \\
\hline Less than $\$ 30,000$ & 0.291 & 0.009 & 0.493 & 0.500 & 0.407 & 0.492 & 0.386 & 0.487 \\
\hline$\$ 30,000-50,000$ & 0.196 & 0.007 & 0.665 & 0.472 & 0.521 & 0.500 & 0.550 & 0.498 \\
\hline$\$ 50,000-75,000$ & 0.166 & 0.006 & 0.778 & 0.416 & 0.597 & 0.491 & 0.650 & 0.477 \\
\hline$\$ 75,000-100,000$ & 0.124 & 0.005 & 0.828 & 0.378 & 0.607 & 0.489 & 0.755 & 0.430 \\
\hline$\$ 100,000-150,000$ & 0.124 & 0.005 & 0.888 & 0.315 & 0.650 & 0.477 & 0.800 & 0.400 \\
\hline$\$ 150,000$ or more & 0.099 & 0.004 & 0.921 & 0.269 & 0.693 & 0.462 & 0.861 & 0.346 \\
\hline \multicolumn{9}{|l|}{ Education } \\
\hline Less than HS & 0.067 & 0.006 & 0.374 & 0.485 & 0.297 & 0.458 & 0.336 & 0.473 \\
\hline High School & 0.282 & 0.009 & 0.590 & 0.492 & 0.454 & 0.498 & 0.453 & 0.498 \\
\hline Some college & 0.317 & 0.008 & 0.692 & 0.462 & 0.555 & 0.497 & 0.596 & 0.491 \\
\hline College & 0.183 & 0.005 & 0.860 & 0.347 & 0.634 & 0.482 & 0.771 & 0.420 \\
\hline Post-Graduate & 0.151 & 0.004 & 0.920 & 0.272 & 0.692 & 0.462 & 0.834 & 0.372 \\
\hline \multicolumn{9}{|c|}{ How closely following news about COVID-19? } \\
\hline Very closely & 0.404 & 0.008 & 0.812 & 0.390 & 0.600 & 0.490 & 0.707 & 0.455 \\
\hline Fairly closely & 0.463 & 0.009 & 0.705 & 0.456 & 0.536 & 0.499 & 0.595 & 0.491 \\
\hline Not too / at all closely & 0.133 & 0.007 & 0.394 & 0.489 & 0.402 & 0.491 & 0.338 & 0.473 \\
\hline \multicolumn{9}{|l|}{$\underline{\text { Age }}$} \\
\hline $18-29$ & 0.189 & 0.008 & 0.501 & 0.500 & 0.473 & 0.500 & 0.498 & 0.500 \\
\hline $30-49$ & 0.343 & 0.008 & 0.697 & 0.460 & 0.556 & 0.497 & 0.625 & 0.484 \\
\hline $50-64$ & 0.261 & 0.007 & 0.763 & 0.426 & 0.542 & 0.498 & 0.619 & 0.486 \\
\hline $65+$ & 0.208 & 0.006 & 0.842 & 0.365 & 0.592 & 0.492 & 0.658 & 0.474 \\
\hline Gender (woman) & 0.518 & 0.009 & 0.646 & 0.478 & 0.525 & 0.499 & 0.587 & 0.492 \\
\hline \multicolumn{9}{|l|}{$\underline{\text { Religion }}$} \\
\hline Conservative Protestant & 0.229 & 0.007 & 0.657 & 0.475 & 0.507 & 0.500 & 0.545 & 0.498 \\
\hline Liberal Protestant & 0.152 & 0.006 & 0.700 & 0.459 & 0.570 & 0.495 & 0.609 & 0.488 \\
\hline Catholic & 0.188 & 0.006 & 0.743 & 0.437 & 0.550 & 0.498 & 0.607 & 0.489 \\
\hline Other & 0.080 & 0.004 & 0.777 & 0.417 & 0.639 & 0.481 & 0.644 & 0.479 \\
\hline Nonreligious & 0.351 & 0.008 & 0.708 & 0.455 & 0.533 & 0.499 & 0.636 & 0.481 \\
\hline
\end{tabular}


adjusted for survey sampling. As the table demonstrates, there are dramatic descriptive disparities among demographic groups in the proportion of the population answering each question correctly.

\section{Models: Survey-Weighted Logistic Regressions}

For my formal models, I analyze the likelihood of answering correctly (compared to incorrectly). Because the outcomes are dichotomous (correct answer $=1$, incorrect $=0$ ), I analyze the data using survey-weighted logistic regression models. Logistic regression assumes that the distribution of repeated Bernoulli trials of the dependent variable (accurate knowledge) follows the binomial distribution. Hence, the probability of the respondent having accurate COVID-19 knowledge is linked to the set of independent variables through the logistic function

$$
\ln \left(\frac{P(y=1)}{P(y=0)}\right)=x \beta
$$

In this model, $x$ is a vector of independent predictor variables, and $\beta$ is a vector of parameter estimates that measure the effect of the $x$ vector on the log odds that the outcome variable $y=1$. I follow the guidance provided by the Pew Research Center for implementing its complex survey weights to account for the sampling design. All analyses were completed using Stata/MP 16.1.

To assess the role of news consumption and demographic groups in acquiring accurate knowledge about the COVID-19 pandemic, I build three weighted logistic regression models for each outcome. For each model, I compute the F-adjusted mean residual test to calculate goodness of fit statistics for each model that takes the survey design into account (Archer \& Lemeshow, 2006).

To aid in model interpretation, I also calculate average predicted probabilities. Interpretations of predicted probabilities can be understood as the probability of the outcome $(y=1)$, conditional on changes in the variable of interest. To calculate these values, I use the Stata margins command. The predicted probabilities are calculated using the observed values of the variables other than the variable of interest, and then averaged.

\section{RESULTS}

I analyze the effect of news source and sociodemographics on the odds that people have correct knowledge about COVID-19-related topics. As Table 3 indicates, I analyzed a series of nested models. For each knowledge question, Model A presents the baseline models predicting correct knowledge for each of the knowledge questions as a function of the variable indicating the source relied on most for news about COVID-19. Model B introduces the moderator variables of class (income and education) and race and ethnicity, allowing us to compare the relative contributions of these and news sources in predicting correct knowledge. In these models, race and ethnicity, family income, and education are important predictors of being correct across all three knowledge questions. Finally, Model C introduces control variables, allowing us to see that confounding variables do not affect the substantive findings in most cases. 
Table 3. Logistic regression predicting correct answers on each knowledge question: odds ratios and SE (in parentheses). Note: *** $\mathrm{p}<0.001, * * \mathrm{p}<0.01, * \mathrm{p}<0.05$

\begin{tabular}{|c|c|c|c|c|c|c|c|c|c|}
\hline & & (1) Fauci & & 1 & ate Response & & & (3) Antibody & \\
\hline & $\begin{array}{c}(1 \mathrm{~A}) \\
\text { News Source }\end{array}$ & $\begin{array}{c}(1 \mathrm{~B}) \\
\text { Class/Race }\end{array}$ & $\begin{array}{c}(1 \mathrm{C}) \\
\text { Controls }\end{array}$ & $\begin{array}{l}(2 \mathrm{~A}) \\
-\end{array}$ & (2B) & $(2 \mathrm{C})$ & (3A) & (3B) & (3C) \\
\hline News Source relies mos & ws about coron & rus outbreak & $\frac{\text { Controls }}{\text { f: Public Healt }}$ & & Class/Race & Controls & & & \\
\hline Int'1/Nat'l & $\begin{array}{l}1.635^{* * *} \\
(0.213)\end{array}$ & $\begin{array}{c}1.832 * * * \\
(0.257)\end{array}$ & $\begin{array}{l}1.509 * * \\
(0.219)\end{array}$ & $\begin{array}{c}1.129 \\
(0.111)\end{array}$ & $\begin{array}{c}1.163 \\
(0.117)\end{array}$ & $\begin{array}{c}1.107 \\
(0.112)\end{array}$ & $\begin{array}{c}1.019 \\
(0.111)\end{array}$ & $\begin{array}{c}1.055 \\
(0.126)\end{array}$ & $\begin{array}{c}0.987 \\
(0.121)\end{array}$ \\
\hline Local & $\begin{array}{l}0.533 * * * \\
(0.0704)\end{array}$ & $\begin{array}{c}0.828 \\
(0.125)\end{array}$ & $\begin{array}{c}0.848 \\
(0.130)\end{array}$ & $\begin{array}{l}0.576 * * * \\
(0.0673)\end{array}$ & $\begin{array}{c}0.750^{*} \\
(0.0911)\end{array}$ & $\begin{array}{c}0.766^{*} \\
(0.0932)\end{array}$ & $\begin{array}{l}0.404 * * * \\
(0.0492)\end{array}$ & $\begin{array}{l}0.578 * * * \\
(0.0791)\end{array}$ & $\begin{array}{l}0.621 * * * \\
(0.0876)\end{array}$ \\
\hline Politicians & $\begin{array}{l}1.334 * \\
(0.174)\end{array}$ & $\begin{array}{l}1.598^{* *} \\
(0.230)\end{array}$ & $\begin{array}{l}1.374^{*} \\
(0.205)\end{array}$ & $\begin{array}{l}1.020 \\
(0.105)\end{array}$ & $\begin{array}{l}1.128 \\
(0.120)\end{array}$ & $\begin{array}{l}1.090 \\
(0.118)\end{array}$ & $\begin{array}{l}0.889 \\
(0.101)\end{array}$ & $\begin{array}{c}0.957 \\
(0.119)\end{array}$ & $\begin{array}{c}0.979 \\
(0.126)\end{array}$ \\
\hline Informal & $\begin{array}{l}0.303 * * * \\
(0.0517)\end{array}$ & $\begin{array}{c}0.429 * * * \\
(0.0805)\end{array}$ & $\begin{array}{l}0.575 * * \\
(0.111)\end{array}$ & $\begin{array}{l}0.567 * * * \\
(0.0934)\end{array}$ & $\begin{array}{c}0.755 \\
(0.129)\end{array}$ & $\begin{array}{c}0.837 \\
(0.146)\end{array}$ & $\begin{array}{c}0.360 * * * \\
(0.0603)\end{array}$ & $\begin{array}{c}0.521 * * * \\
(0.0988)\end{array}$ & $\begin{array}{l}0.652^{*} \\
(0.128)\end{array}$ \\
\hline Race/Ethnicity (ref:Wl & & & & & & & & & \\
\hline Black & & $\begin{array}{l}0.460 * * * \\
(0.0674)\end{array}$ & $\begin{array}{l}0.479 * * * \\
(0.0749)\end{array}$ & & $\begin{array}{l}0.532 * * * \\
(0.0661)\end{array}$ & $\begin{array}{l}0.520 * * * \\
(0.0675)\end{array}$ & & $\begin{array}{l}0.301 * * * \\
(0.0388)\end{array}$ & $\begin{array}{c}0.274 * * * \\
(0.0361)\end{array}$ \\
\hline Asian & & $\begin{array}{l}0.488 * * \\
(0.129)\end{array}$ & $\begin{array}{l}0.530^{*} \\
(0.134)\end{array}$ & & $\begin{array}{c}0.784 \\
(0.153)\end{array}$ & $\begin{array}{c}0.761 \\
(0.149)\end{array}$ & & $\begin{array}{c}0.336 * * * \\
(0.0666)\end{array}$ & $\begin{array}{l}0.330 * * * \\
(0.0657)\end{array}$ \\
\hline Hispanic & & $\begin{array}{l}0.516^{* * *} \\
(0.0649)\end{array}$ & $\begin{array}{c}0.627 * * * \\
(0.0879)\end{array}$ & & $\begin{array}{c}0.822 \\
(0.0919)\end{array}$ & $\begin{array}{c}0.868 \\
(0.102)\end{array}$ & & $\begin{array}{l}0.473 * * * \\
(0.0563)\end{array}$ & $\begin{array}{l}0.471 * * * \\
(0.0610)\end{array}$ \\
\hline Other/mixed & & $\begin{array}{c}0.596 \\
(0.164)\end{array}$ & $\begin{array}{c}0.722 \\
(0.199)\end{array}$ & & $\begin{array}{c}0.794 \\
(0.175)\end{array}$ & $\begin{array}{c}0.800 \\
(0.177)\end{array}$ & & $\begin{array}{c}0.505^{* *} \\
(0.111)\end{array}$ & $\begin{array}{l}0.499 * * \\
(0.116)\end{array}$ \\
\hline Family Income (ref: les & $.000)$ & & & & & & & & \\
\hline$\$ 30,000-50,000$ & & $\begin{array}{c}1.641 * * * \\
(0.206)\end{array}$ & $\begin{array}{c}1.594 * * * \\
(0.209)\end{array}$ & & $\begin{array}{l}1.327^{*} \\
(0.155)\end{array}$ & $\begin{array}{l}1.307^{*} \\
(0.154)\end{array}$ & & $\begin{array}{c}1.566 * * * \\
(0.183)\end{array}$ & $\begin{array}{c}1.552 * * * \\
(0.186)\end{array}$ \\
\hline$\$ 50,000-75,000$ & & $\begin{array}{c}2.452 * * * \\
(0.341)\end{array}$ & $\begin{array}{c}2.300 * * * \\
(0.323)\end{array}$ & & $\begin{array}{c}1.654 * * * \\
(0.193)\end{array}$ & $\begin{array}{c}1.607 * * * \\
(0.188)\end{array}$ & & $\begin{array}{c}2.038 * * * \\
(0.243)\end{array}$ & $\begin{array}{c}2.006^{* * * *} \\
(0.245)\end{array}$ \\
\hline$\$ 75,000-100,000$ & & $\begin{array}{c}2.952 * * * \\
(0.478)\end{array}$ & $\begin{array}{c}2.688^{* * * *} \\
(0.443)\end{array}$ & & $\begin{array}{c}1.577 * * * \\
(0.189)\end{array}$ & $\begin{array}{c}1.534 * * * \\
(0.184)\end{array}$ & & $\begin{array}{c}3.032 * * * \\
(0.418)\end{array}$ & $\begin{array}{c}3.051 * * * \\
(0.426)\end{array}$ \\
\hline$\$ 100,000-150,000$ & & $\begin{array}{c}3.915^{* * *} \\
(0.612)\end{array}$ & $\begin{array}{c}3.565^{* * *} \\
(0.634)\end{array}$ & & $\begin{array}{c}1.721^{* * *} \\
(0.201)\end{array}$ & $\begin{array}{l}1.652 * * * \\
(0.197)\end{array}$ & & $\begin{array}{c}3.281 * * * \\
(0.441)\end{array}$ & $\begin{array}{c}3.267 * * * \\
(0.458)\end{array}$ \\
\hline$\$ 150,000$ or more & & $\begin{array}{c}5.339 * * * \\
(1.222)\end{array}$ & $\begin{array}{c}4.403 * * * \\
(0.998)\end{array}$ & & $\begin{array}{c}1.937 * * * \\
(0.250)\end{array}$ & $\begin{array}{c}1.826 * * * \\
(0.241)\end{array}$ & & $\begin{array}{c}4.603 * * * \\
(0.806)\end{array}$ & $\begin{array}{c}4.262^{* * * *} \\
(0.778)\end{array}$ \\
\hline Education (ref: less tha & (ool) & & & & & & & & \\
\hline High School & & $\begin{array}{l}1.856^{* *} \\
(0.397)\end{array}$ & $\begin{array}{c}2.106^{* *} \\
(0.491)\end{array}$ & & $\begin{array}{l}1.678^{*} \\
(0.352)\end{array}$ & $\begin{array}{l}1.710^{*} \\
(0.359)\end{array}$ & & $\begin{array}{l}1.146 \\
(0.261)\end{array}$ & $\begin{array}{c}1.219 \\
(0.290)\end{array}$ \\
\hline Some college & & $\begin{array}{c}2.489 * * * \\
(0.516)\end{array}$ & $\begin{array}{c}3.191 * * * \\
(0.721)\end{array}$ & & $\begin{array}{c}2.337 * * * \\
(0.471)\end{array}$ & $\begin{array}{c}2.355 * * * \\
(0.475)\end{array}$ & & $\begin{array}{l}1.792 * * \\
(0.394)\end{array}$ & $\begin{array}{l}1.825^{* *} \\
(0.420)\end{array}$ \\
\hline College & & $\begin{array}{c}5.036^{* * *} \\
(1.091)\end{array}$ & $\begin{array}{c}6.525 * * * \\
(1.551)\end{array}$ & & $\begin{array}{c}2.758^{* * *} \\
(0.565)\end{array}$ & $\begin{array}{c}2.709 * * * \\
(0.558)\end{array}$ & & $\begin{array}{c}3.109 * * * \\
(0.703)\end{array}$ & $\begin{array}{c}3.008 * * * \\
(0.712)\end{array}$ \\
\hline Post-graduate & & $\begin{array}{c}7.654 * * * \\
(1.788)\end{array}$ & $\begin{array}{c}9.348^{* * *} \\
(2.386)\end{array}$ & & $\begin{array}{c}3.284 * * * \\
(0.689)\end{array}$ & $\begin{array}{c}3.135 * * * \\
(0.663)\end{array}$ & & $\begin{array}{c}4.048^{* * *} \\
(0.951)\end{array}$ & $\begin{array}{c}3.938 * * * \\
(0.967)\end{array}$ \\
\hline How closely following & COVID-19? & Not too/at a & $\begin{array}{l}\text { closely) } \\
\text { (2.300) }\end{array}$ & & & & & & \\
\hline Very closely & & & $\begin{array}{c}3.708 * * * \\
(0.571)\end{array}$ & & & $\begin{array}{c}1.676 * * * \\
(0.224)\end{array}$ & & & $\begin{array}{c}3.659 * * * \\
(0.523)\end{array}$ \\
\hline Fairly closely & & & $\begin{array}{c}2.393 * * * \\
(0.352)\end{array}$ & & & $\begin{array}{l}1.362^{*} \\
(0.180)\end{array}$ & & & $\begin{array}{c}2.265 * * * \\
(0.315)\end{array}$ \\
\hline Age (ref: 18-29) & & & & & & & & & \\
\hline $30-49$ & & & $1.554 * *$ & & & 1.093 & & & 1.060 \\
\hline
\end{tabular}




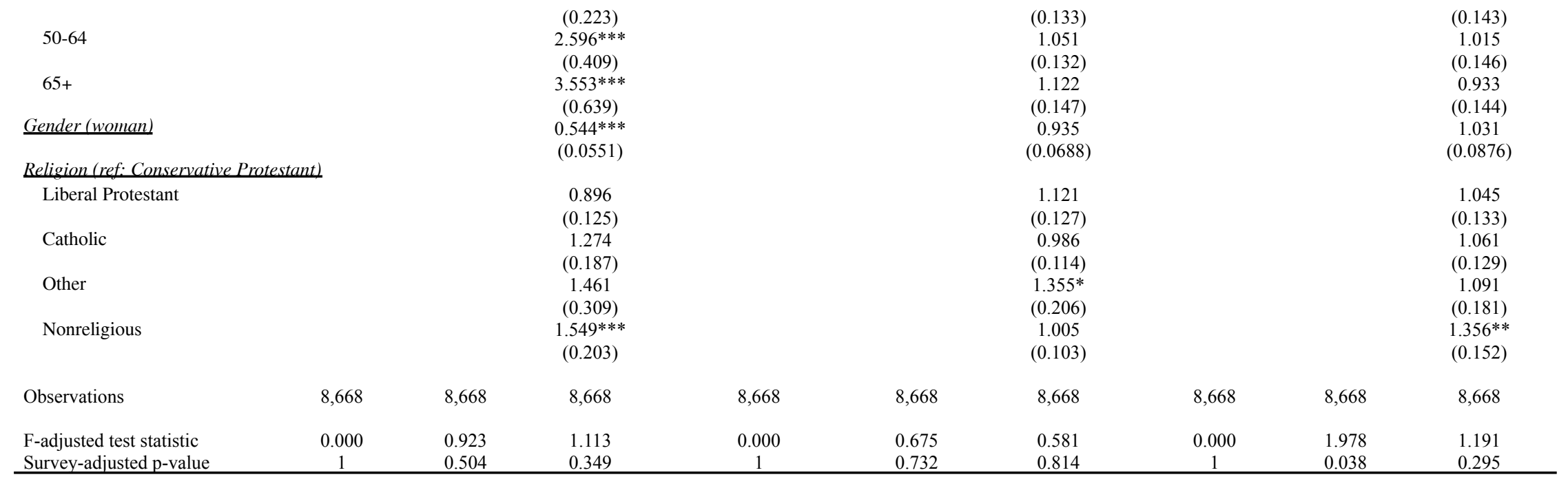




\section{COVID Knowledge by News Source}

Notably, those who report primarily getting their news about COVID-19 through national and international news sources or from politicians are the most likely to answer all three questions correctly (models A). Those who rely primarily on international or national news or politicians for information about COVID-19 were more likely than those relying on local or informal news to correctly answer each knowledge question, controlling for age, gender, race and ethnicity, family income, education, religion, and how carefully they followed the news (models C). I therefore find support for hypothesis 1 , finding that those who consume the most news from national or international sources have more knowledge about COVID-19 topics than those acquiring news from local sources.

Respondents who report consuming their news from any other source besides international or international news or politicians (including, surprisingly, public health officials) were significantly less likely to correctly identify Anthony Fauci's role as "an infectious disease expert and government health adviser" (model 1A). The same held true once control variables were added (model 1C). However, those who primarily relied on public health officials for their news about COVID-19 were equally likely as those who primarily relied on international or national news or politicians to answer the questions about state responses (models $2 \mathrm{~A}$ and 2C) and antibodies (models $3 \mathrm{~A}$ and 3C). Therefore, I find mixed support for hypothesis 2 , as those who consume the most news from public health sources sometimes had more accurate knowledge about COVID-19 topics than those acquiring news from political sources, but sometimes did not. Respondents who report relying on political officials for their news are equally likely as those who rely on international or national news to answer the COVID-19 knowledge questions correctly, across all models and questions (models A, $\mathrm{B}$, and $\mathrm{C})$.

Those who received their information primarily from local news were significantly less likely than those relying on public health officials or international or national sources for their news to have accurate knowledge about each of the topics. The one exception to this is the model predicting knowledge of Fauci's role with controls (model 1C), where the addition of the control variables eliminated the significance of the local news coefficient relative to those relying on public health officials. We also see that the effect of reliance on local news in knowledge of statewide stay-at-home orders is somewhat moderated by the addition of the control variables (from model 2A to 2C).

Drilling down into this a bit more, I find that those who rely on state and local elected officials or community or neighborhood newsletters or listservs for their information were just as likely as those relying on national or international news or on public health officials to know that some states did not have statewide orders, all other variables held constant (see online supplementary Table A1 at osf.io/qf624/). This is an interesting contrast to those relying on local news; it seems that the particular form of local information matters when it comes to having accurate knowledge about nationwide events.

Those who reported relying on informal sources of information about COVID-19 were the most likely to be incorrect about each of the questions (models A). With the addition of controls, this relationship persisted for knowledge of Fauci (model 1C) and antibodies (model 3C) but not state

Preprint v2 | September 22, 2021 
response (model 2C). Those who report relying on local news and informal sources are equally likely to be the least knowledgeable about antibodies, controlling for all else (model 3C). Specifically, relying on friends, family, and neighbors for information about COVID-19 was the most consistent predictor of a lack of knowledge about COVID-19 topics, particularly Fauci and state response, holding constant all else (see online supplementary Table A1). Those relying on community or neighborhood newsletters or listservs were also significantly more likely to be incorrect about the antibody question, though clear conclusions are difficult because of small sample sizes (see online supplementary Table A1). I therefore find support for hypothesis 3, finding that those who consume the most news from formal sources have more knowledge about COVID-19 topics than those acquiring news from informal sources.

Each knowledge question has its own unique fingerprint of which news sources make respondents most likely to have correct knowledge about that topic. The government operations-focused question about Fauci is most likely to be known by those who rely on international or national sources or politicians for their news (model 1). Details about state stay-at-home orders, related to health policy, are most familiar to those following public health officials, national and international sources, and politicians (model 2). The scientific facts about antibody tests are best known to those following international or national sources, public health officials, and politicians (model 3). The consumption of knowledge is contextual, and the sources from which we consume accurate knowledge vary depending on the topic.

\section{Moderation Models}

Model B (Table 3) introduces the moderation variables of race and ethnicity, family income, and educational attainment for each knowledge question. We see that with the introduction of these variables, the magnitude of the effect of the news source variables generally increases. Therefore, across the three questions, we do find support for hypothesis 4, finding that race and ethnicity, family income, and educational attainment jointly moderate the relationship between news source and knowledge. Model $\mathrm{C}$ adds control variables to these moderation models.

\section{Race and Ethnicity}

All models show a significant effect of some feature of race and ethnicity of the respondent on the likelihood of knowing the correct answer to the question (Table 3). There is a significant negative effect of being Black (compared to being white) on the odds of knowing the correct answer to each question. The effect is striking: Black people are only about half as likely (or less) to know the answer to each question, controlling for income, education, news source (models B), age, gender, and religion (models $\mathrm{C}$ ). There are similar negative effects of being Asian and Hispanic, although the magnitudes are not as great (models $1 \mathrm{C}$ and 3C), and the effects are not significant for the state response question (model $2 \mathrm{C}$ ). These findings for Asians and Hispanics could be a result of small sample sizes. Figure 1 displays average predicted probabilities (based on model C) of answering correctly for each racial group for each knowledge question. I do find moderate support for hypothesis 5 . 
Figure 1. Average predicted probabilities of answering correctly by race and ethnicity for each COVID-19 knowledge question. Calculations are based on the full model C from Table 3 and weighted for the survey sampling design. Data: Pew June 2020 American Trends Panel Wave 68 survey.

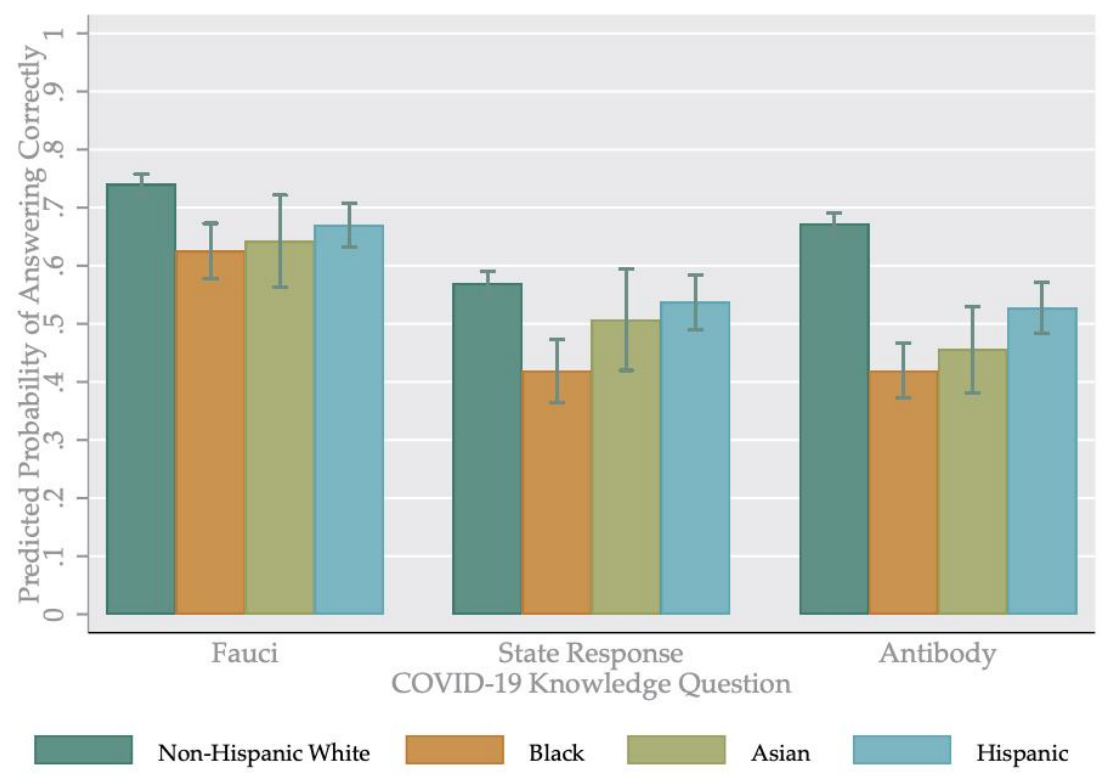

\section{Family Income}

Across all models and questions, family income has a significant effect on how likely people are to be knowledgeable about COVID-19 topics. The addition of education into the models reduces the magnitude of the effect of income on the likelihood of knowing the correct answer, but in no case does it eliminate the effect altogether. Each additional categorical increase in family income increases the odds of knowing who Fauci is, holding constant race and ethnicity, education, news source (model 1B), gender, age group, and religion (model 1C). Each additional increase in family income level also significantly increases the odds of knowing that some states did not have a stay at home order, except for family income range between $\$ 50,000$ and $\$ 100,000$, where the categories of $\$ 50,000$ to $\$ 75,000$ and $\$ 75,00$ to $\$ 100,000$ are statistically indistinguishable from each other (models 2B and 2C). Additional family income also increases the odds of knowing that antibody tests are intended to detect previous infection, controlling for race and ethnicity, education, news source (model 3B), gender, age group, and religion (model 3C). Figure 2 presents predicted probabilities of answering the questions about COVID-19 correctly as a function of family income. We do find support for hypothesis 6, finding that those with higher family incomes will have more knowledge about COVID-19 topics. Overall, family income has a positive and significant effect on the likelihood of having accurate knowledge of COVID-19 topics in the three different knowledge areas: government operations, public health, and scientific knowledge. 
Figure 2. Average predicted probabilities of answering correctly by family income category for each COVID-19 knowledge question. Calculations are based on the full model C from Table 3 and weighted for the survey sampling design. Data: Pew June 2020 American Trends Panel Wave 68 survey.

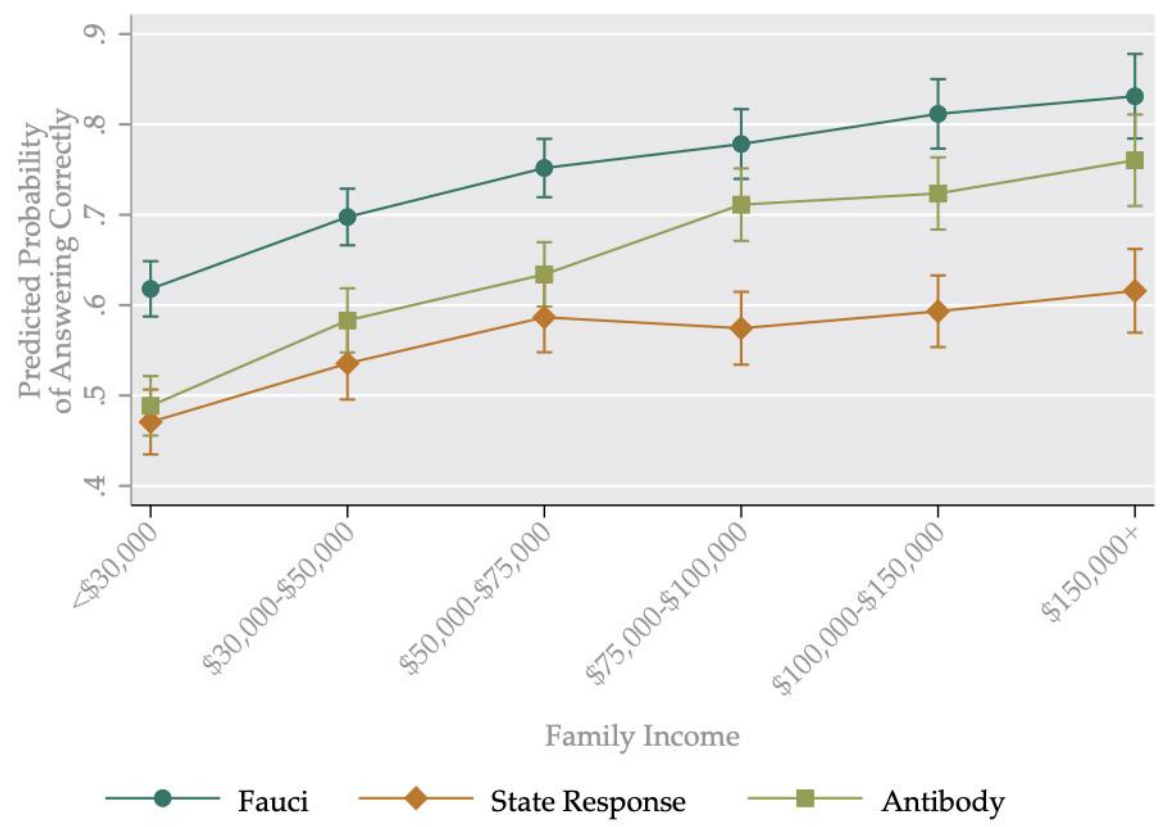

Figure 3. Average predicted probabilities of answering correctly by educational attainment for each COVID-19 knowledge question. Calculations are based on the full model C from Table 3 and weighted for the survey sampling design. Data: Pew June 2020 American Trends Panel Wave 68 survey.

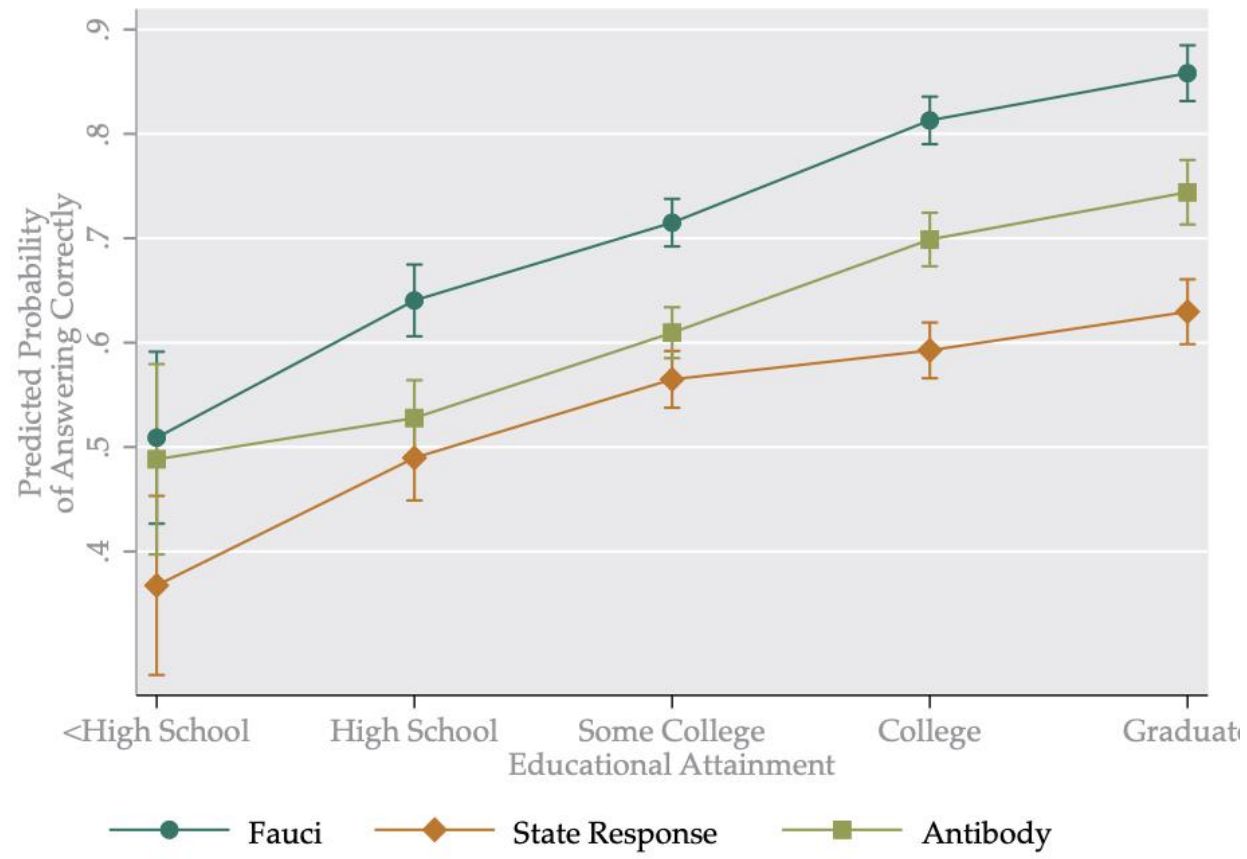

Preprint v2 | September 22, 2021 


\section{Education}

Each additional level of educational attainment significantly increases the odds of answering correctly for all knowledge questions (models B and C) except for high school in knowledge of the antibody question (models 3B and 3C), compared to less than high school. Considering that the effect holds where family income is also controlled, this speaks to the importance of education in acquiring and digesting information in order to attain accurate knowledge about COVID-19. Adding in controls does somewhat reduce the magnitude of the effect of education, but it does not eliminate its significance. Figure 3 presents predicted probabilities of answering each question correctly based on educational attainment. We do find support for hypothesis 7, finding that those with more education do have more knowledge about COVID-19 topics.

\section{DisCUSSION}

How do we come to know what we know? How do we come to be misinformed? Both, often through engagement with news media and informal sources. Individuals face the world with different sets of knowledge, shaped by their social contexts. Some of this knowledge may be correct, and some of it may be incorrect, as we see in the results of this analysis. This study documents concrete evidence on different groups' command over different types of knowledge resources, a matter of increasing importance in modern society. By understanding how knowledge of the COVID-19 pandemic has been classed and raced through mechanisms of knowledge acquisition, it contributes in the style of Mannheim's sociology of knowledge (Mannheim, 1929; Swidler \& Arditi, 1994). Much of the recent work on media consumption looks at demographic differences in trust in different news sources. While trust and knowledge are related, trust does not tell us the whole story of the foundation of knowledge different groups have upon which to act (Evans \& Hargittai, 2020; Fridman et al., 2020). This paper describes the current state of COVID-19 knowledge in the U.S. as a function of news consumption, race and ethnicity, income, and education, distinct from trust in the news-providing institution.

There are clear patterns in the efficacy of different media consumption. I find that those who rely on international or national news, politicians, or public health officials for their news about the coronavirus outbreak are the most likely to have accurate knowledge across all three questions, with some minor variations. Local and informal sources of news are the least likely to correlate with accurate knowledge of COVID-19 topics. This is consistent with the research, discussed in the introduction, that finds the greatest concern about misinformation among those seeking news on social media (Mitchell et al., 2020; Newman et al., 2020). This is further exacerbated by the fact that those with lower incomes and less education -- two characteristics which I find further disadvantaged people in their knowledge of COVID-19 topics -- are more likely to turn to these news outlets for their news (Mitchell et al., 2020).

This finding that local and informal news sources are associated with less accurate knowledge of COVID-19 is particularly notable given recent efforts to 'democratize' the news media (Deane, 2005). One possible reason for this is Sinclair Broadcasting Group’s purchase of many small local news stations (currently 186 according to its own website), often using these platforms to promote a conservative political stance and misinformation about Democratic party viewpoints (Tryon, 2020). 
In the past year, COVID-19 knowledge has often been politicized in the news (Rothgerber et al., 2020). These findings also point to a need for local news to more carefully cover emerging information about government, public health, and scientific issues using fact-based journalism in accessible formats to promote understanding. Social media companies also face significant challenges in moderating misinformation on their platforms.

My results show that there are also clear demographic distinctions in who knows what about the coronavirus pandemic. Being Black makes one significantly less likely to have correct knowledge about COVID-19 topics related to government, public health, and science. Being Asian or Hispanic makes one less likely to correctly answer the questions about Fauci or antibody tests, but no less likely to correctly answer the questions about state responses, compared to whites and holding all else constant. Class has a mostly unidirectional effect on knowledge: the higher one's income or educational attainment, the greater one's knowledge of COVID-19 topics, all else equal (with nonsignificant exceptions between $\$ 50,000$ and $\$ 100,000$ for knowledge of state responses in models 2B and 2C). Education also has persistent effects on the odds of accurate knowledge, although its magnitude varies by whether the question is focused on governmental, public health, or scientific knowledge. Future research could explore these dynamics further using interaction or subset analyses. I performed some preliminary exploratory analyses of interaction effects between race and news source, and did not find many significant variations from the main findings (see online Table A3 at osf.io/qf624). I still find that both news source and demographic characteristics of class and race are significant predictors of whether people have accurate knowledge of COVID-19 topics.

These sociodemographic-based gaps have implications not only for knowledge but also other life outcomes, as well. This is because we use accurate knowledge to pragmatically guide action: "Ultimately, we care about truth (at least scientific truth) inasmuch as true beliefs allow us to act successfully in the world. We care about knowledge because of the role that what we know -- or what we strongly believe to be true -- plays in and the choices we make, either individually or collectively" (O’Connor \& Weatherall, 2019, p. 29). Gaps in knowledge produce inequalities in later outcomes, including some vital to health during COVID-19. Accurate health knowledge is necessary (though not sufficient) to affect health behavior (HINTS, 2008).

Correct knowledge is a required foundation that is both influenced by and built upon by structural inequalities. Those with accurate knowledge about COVID-19 are more likely to have positive health outcomes during the pandemic (Fridman et al., 2020). Because of systemic racism, Black Americans are at greater risk of contracting and dying from COVID-19 (Price-Haywood, Burton, Fort, \& Seoane, 2020). This is one reason the racial gaps in the measures of knowledge of public health and scientific knowledge are so potentially consequential. One might expect groups at greater risk to more closely follow news about the COVID-19 pandemic; this is the case among Black Americans (Mitchell \& Jurkowitz, 2020). However, despite this, non-whites, and especially Black Americans, had lower levels of knowledge on all COVID-19 topics, controlling for education and income. Some initial work suggests that messenger-recipient racial concordance is important for promoting knowledge-seeking among Black people, while concordance on other characteristics may be more important among Latinx communities (Cooper \& Stoney, 2021). A better understanding of the origins of and solutions for gaps in knowledge is an urgent issue that demands further research. 
The modern networked press is increasingly distributed across journalistic organizations but also other sociotechnical institutions and many publics (Ananny, 2020). Understanding how news source, class, and race affect the process of acquiring accurate knowledge about COVID-19 in the U.S. helps us understand how people acquire accurate knowledge more generally. With a better understanding of the ways social contexts shape knowledge and gaps in knowledge, we can design better systems to improve information accuracy and knowledge dissemination in the media, government, and other sociotechnical institutions. 
Ananny, M. (2020). Advocating for What? The Nonprofit Press and Models of the Public. In W. W. Powell \& P. Bromley (Eds.), The Nonprofit Sector: A Research Handbook (pp. 521-538). Stanford, CA: Stanford University Press.

Archer, K. J., \& Lemeshow, S. (2006). Goodness-of-fit test for a logistic regression model fitted using survey sample data. Stata Journal, 6(1), 97-105.

Bachmann, P., Eisenegger, M., \& Ingenhoff, D. (2021). Defining and Measuring News Media Quality: Comparing the Content Perspective and the Audience Perspective. The International Journal of Press/Politics 194016122199966.

Baker, J. O., Perry, S. L., \& Whitehead, A. L. (2020). Crusading for Moral Authority: Christian Nationalism and Opposition to Science. Sociological Forum, 35(3), 587-607.

Baum, M., Lin, J., Ognyanova, K., Chwe, H., Quintana, A., Lazer, D., ... Green, J. (2020). Report \#13: Public Trust in Institutions and Vaccine Acceptance. The State Of The Nation: A 50-State COVID-19 Survey. Retrieved from 10.31219/osf.io/qzsxn

Baum, M., Ognyanova, K., Chwe, H., Quintana, A., Perlis, R. H., Lazer, D., ... Green, J. (2020). Report \#14: Misinformation And Vaccine Acceptance. The State Of The Nation: A 50-State COVID-19 Survey.

Britz, J. J. (2004). To Know or not to Know: A Moral Reflection on Information Poverty. Journal of Information Science, 30(3), 192-204.

Camic, C., \& Gross, N. (2001). The New Sociology of Ideas. In J. R. Blau (Ed.), The Blackwell Companion to Sociology (pp. 236-249). Blackwell Publishing Ltd.

Case, D. O., \& Given, L. M. (2016). Looking for Information: A Survey of Research on Information Seeking, Needs, and Behavior (4th ed.). Bingley, UK: Emerald Group Publishing Limited.

Cooper, L. A., \& Stoney, C. M. (2021). Messages to Increase COVID-19 Knowledge in Communities of Color: What Matters Most? Annals of Internal Medicine, 174(4), 554-555.

Deane, J. (2005). Media, democracy and the public sphere. In Media \& Glocal Change: Rethinking Communication for Development (pp. 177-192). Buenos Aires: Consejo Latinoamericano de Ciencias Sociales.

Diakopoulos, N. (2019, May 10). Audit suggests Google favors a small number of major outlets. Columbia Journalism Review. Retrieved from https:/ /www.cjr.org/tow_center/google-news-algorithm.php

DiMaggio, P. J. (1997). Culture and Cognition. Annual Review of Sociology 23, 263-287.

Eubanks, V. (2018). Automating Inequality: How High-Tech Tools Profile, Police, and Punish the Poor. St. Martin's Press.

Evans, J. H. (2018). Morals Not Knowledge: Recasting the Contemporary U.S. Conflict between Religion and Science. San Diego, CA: University of California Press.

Evans, J. H., \& Evans, M. S. (2008). Religion and science: Beyond the epistemological conflict narrative. Annual Review of Sociology 34, 87-105.

Evans, J. H., \& Hargittai, E. (2020). Who Doesn't Trust Fauci? The Public's Belief in the Expertise and Shared Values of Scientists in the COVID-19 Pandemic. Socius: Sociological Research for a Dynamic World, 6, 237802312094733.

Fischer, S., Jaidka, K., \& Lelkes, Y. (2020). Auditing local news presence on Google News. Nature Human Behaviour, 4(December).

Fisher, C. (2016). The trouble with 'trust' in news media. Communication Research and Practice, 2(4), 
451-465.

Freese, J., \& King, M. M. (2018). Institutionalizing Transparency. Socius: Sociological Research for a Dynamic World, 4, 1-7.

Fridman, I., Lucas, N., Henke, D., \& Zigler, C. K. (2020). Association Between Public Knowledge About COVID-19, Trust in Information Sources, and Adherence to Social Distancing: Cross-Sectional Survey. JMIR Public Health and Surveillance, 6(3), e22060.

Gamble, V. N. (1997). Under the Shadow of Tuskegee: African Americans and Health Care. Am J Public Health, 87, 1773-1778.

HINTS. (2008). Only 28\% Know Lung Cancer Is the Leading Cause of Cancer Deaths 84\% Retrieved from hints.cancer.gov

Howell, J., \& Emerson, M. O. (2017). So What "Should" We Use? Evaluating the Impact of Five Racial Measures on Markers of Social Inequality. Sociology of Race and Ethnicity 3(1), 12-30.

Ichikawa, J. J., \& Steup, M. (2012). The Analysis of Knowledge. Retrieved from https:/ / plato.stanford.edu/entries/knowledge-analysis/

Knight Foundation, \& Gallup. (2019). State of PublicTrust in Local News.

Mannheim, K. (1929). Ideology and Utopia. (L. Wirth \& E. Shils, Trans.). New York: Harcourt, Brace \& Co., Inc.

McFadden, S. A. M., Malik, A. A., Aguolu, O. G., Willebrand, K. S., \& Omer, S. B. (2020). Perceptions of the adult US population regarding the novel coronavirus outbreak. PLoS ONE, 15(4), 1-6.

Metaxa-Kakavouli, D., \& Torres-Echeverry, N. (2017). Google's Role in Spreading Fake News and Misinformation. SSRN Working Paper. https://doi.org/10.2139/ssrn.3062984

Mitchell, A., \& Jurkowitz, M. (2020). Black U.S. adults follow many COVID- 19 news topics more closely, discuss the outbreak more frequently. Retrieved from http://www.pewresearch.org/fact-tank/2018/10/19/5-charts-on-global-views-of-china/

Mitchell, A., Jurkowitz, M., Oliphant, J. B., \& Shearer, E. (2020). Americans Who Mainly Get Their News on Social Media Are Less Engaged, Less Knowledgeable.

Mohammed, S. N. (2012). The (Dis)information Age: The Persistence of Ignorance New York: Peter Lang.

Newman, N., Richard Fletcher, W., Schulz, A., And1, S., \& Kleis Nielsen, R. (2020). Reuters Institute Digital News Report 2020. Retrieved from https://reutersinstitute.politics.ox.ac.uk/sites/default/files/2020-06/DNR_2020_FINAL.pdf

Nielsen, R. K. (2017). Digital news as forms of knowledge: a new chapter in the sociology of knowledge. In P. Boczkowski \& C. W. Anderson (Eds.), Remaking the News: Essays on the Future of Journalism Scholarship in the Digital Age. Cambridge MA: MIT Press. Retrieved from https://papers.ssrn.com/sol3/papers.cfm?abstract_id=2969115

Noble, S. U. (2018). Algorithms of Oppression: HowSearch Engines Reinforce Racism. New York: New York University Press.

O'Connor, C., \& Weatherall, J. O. (2019). The Misinformation Age: How False Beliefs Spread. Yale University Press.

O’Connor, C., \& Weatherall, J. O. (2020). Why False Claims About COVID-19 Refuse to Die: Tracking the information zombie apocalypse. Nautilus. Retrieved from http://nautil.us/issue/84/outbreak/why-false-claims-about-covid_19-refuse-to-die

O’Neil, C. (2016). Weapons of Math Destruction: HowBig Data Increases Inequality and Threatens Democracy. Crown.

Pariser, E. (2011). The Filter Bubble: How the New Personalized Web Is Changing What We Read and How 
We Think. New York: Penguin.

Perry, S. L., Baker, J. O., \& Grubbs, J. B. (2021). Ignorance or culture war? Christian nationalism and scientific illiteracy. Public Understanding of Science 096366252110062.

Pew Research Center. (2017). News Use Across Social Media Platforms 2017. Retrieved from http://www.journalism.org/2017/09/07/news-use-across-social-media-platforms-2017/

Pew Research Center. (2018). Publics Globally Want Unbiased News Coverage, but Are Divided on Whether Their News Media Deliver. Amy Mitchell Katie Simmons Katerina Eva Matsa Laura Silver. Retrieved from https://www.pewresearch.org/global/2018/01/11/publics-globally-want-unbiased-news-cover age-but-are-divided-on-whether-their-news-media-deliver/

Pew Research Center. (2020). Pew Research Center: American Trends Panel Wave 68 [Dataset]. Retrieved from https:/ /www.journalism.org/dataset/american-news-pathways-june-2020-survey/

Price-Haywood, E. G., Burton, J., Fort, D., \& Seoane, L. (2020). Hospitalization and Mortality among Black Patients and White Patients with Covid-19. New England Journal of Medicine 382(26), 2534-2543.

Robinson, L., Schulz, J., Blank, G., Ragnedda, M., Ono, H., Hogan, B., ... Khilnani, A. (2020). Digital inequalities 2.0: Legacy inequalities in the information age. First Monday, (July).

Roos, J. M. (2016). Contested Knowledge and Spillover. Social Currents, 1-20.

Rothgerber, H., Wilson, T., Whaley, D., Rosenfeld, D., Humphrey, M., Moore, A., \& Bihl, A. (2020). Politicizing the COVID-19 Pandemic: Ideological Differences in Adherence to Social Distancing, 1-36.

Shearer, E. (2020). Local news is playing an important role for Americans during COVID-19 outbreak. Pew Research Center. Retrieved from http://www.pewresearch.org/fact-tank/2018/10/19/5-charts-on-global-views-of-china/

Sullivan, L. S. (2020). Trust, Risk, and Race in American Medicine. Hastings Center Report, 50(1), $18-26$.

Swidler, A., \& Arditi, J. (1994). The New Sociology of Knowledge. Annual Review of Sociology 20, 305-329.

Truncellito, D. A. (2021). Epistemology. In Internet Encyclopedia of Philosophy Retrieved from https://iep.utm.edu/epistemo/

Tryon, C. (2020). Sinclair broadcasting as mini-media empire: media regulation, disinfomercials, and the rise of Trumpism. Media, Culture and Society, 42(7-8), 1377-1391.

Yu, L. (2006). Understanding Information Inequality: Making Sense of the Literature of the Information and Digital Divides. Journal of Librarianshipand Information Science, 38(4), 229-252. 